\title{
LEVANTAMENTO DETALHADO DE SOLOS DA MICROBACIA HIDROGRÁFICA DO HORTO FLORESTAL TERRA DURA (RS) E CONSIDERAÇÕES SOBRE ESCALAS DE MAPEAMENTO ${ }^{1}$
}

\author{
Detailed soil survey of the hydrographic small watershed of Terra Dura (RS) forestry garden \\ and considerations about mapping scales
}

\author{
Adriana Monteiro da Costa ${ }^{2}$, Nilton Curi ${ }^{3}$, Michele Duarte de Menezes ${ }^{4}$, \\ Elias Frank de Araújo5, João José Marques ${ }^{3}$
}

\begin{abstract}
RESUMO
A utilização adequada de informações contidas em levantamentos de solos fornece subsídios para o planejamento de diversas áreas de atividade, sejam agrícolas ou não-agrícolas. Entretanto, tem-se observado a ampliação dos mapas de solos de microbacias hidrográficas e de municípios, a partir de mapas de pequena escala, sem trabalhos de campo. Essa prática, no entanto, não é aconselhável, podendo levar à interpretações incorretas. Assim, este trabalho foi desenvolvido com o objetivo de executar o levantamento detalhado de solos de uma microbacia hidrográfica localizada no estado do Rio Grande do Sul e comparar as informações obtidas pelo levantamento detalhado de solos, escala 1:10.000, com aquelas dos mapas ampliados do levantamento de reconhecimento de solos daquele estado, escala 1:750.000, e do levantamento exploratório, escala 1:1.000.000. As unidades de mapeamento de solos foram quantificadas quanto à área de abrangência e porcentagem da área ocupada. O levantamento detalhado permitiu identificar doze unidades de mapeamento de solos na microbacia, ao passo que os mapas ampliados de solos identificaram apenas uma. Em torno de $40 \%$ da área da microbacia, atributos relevantes à aptidão silvicultural das terras para o cultivo do eucalipto não puderam ser adequadamente avaliados pelos mapas de escala pequena ampliados.
\end{abstract}

Termos para indexação: Mapas, ampliação de mapas, tipos de mapas de solos.

\section{ABSTRACT}

The adequate utilization of information gathered from soil survey furnishes subsides for planning projects on diverse areas of activity, being agricultural or non-agricultural. However, it is being observed an increase of soil maps of hydrographic small watersheds and counties developed from small-scale maps without fieldwork. This practice is not recommended since it can lead to wrong interpretations. So, this work had the objective to perform the detailed soil survey of a hydrographic small watershed situated in Rio Grande do Sul State and to compare the information obtained from the detailed soil survey (1:10,000 scale) to those from the amplified maps of reconnaissance soil survey of that state, $(1: 750,000$ scale $)$ and of the exploratory soil survey $(1: 1,000,000$ scale). The soil mapping units were quantified in terms of geographical expression area and percentage of total area. The detailed soil survey identified 12 soil mapping units in the small watershed, while the amplified soil maps identified only one. In about $40 \%$ of the small watershed area, important attributes of forestry suitability for eucalyptus cultivation could not be adequately evaluated from amplified small-scale maps.

Index terms: Maps, map amplification, types of soil maps.

(Recebido em 9 de abril de 2008 e aprovado em 9 de abril de 2009)

\section{INTRODUÇÃO}

A região fisiográfica Depressão Central do Rio Grande do Sul corresponde à área de drenagem do Rio Jacuí e seus afluentes, tendo uso intensivo com citricultura e florestamento com acácia e eucalipto (Streck et al., 2008). Nessa região, como em outras, os mapeamentos de solos para o planejamento de diversas áreas de atividade constituem uma base segura e real (Menezes, 2007), importante para o cenário agrícola atual, que busca maior competitividade bem como a conservação dos recursos naturais (Silva et al., 2008).

O levantamento de solos é importante na estratificação de ambientes, permitindo a previsão de seu comportamento para fins agrícolas (Resende \& Rezende, 1983), planejamentos urbanos, projetos de assentamentos rurais, florestais, de irrigação e drenagem, avaliação para

\footnotetext{
${ }^{1}$ Parte da Tese de Doutorado do primeiro autor apresentada ao Departamento Pós-Graduação em Ciência do Solo da Universidade Federal de Lavras UFLA.

${ }^{2}$ Doutora em Ciência do Solo. Rua Tapajós, 1052 - São Francisco - 35700-511 - Sete Lagoas, MG - drimonteiroc@yahoo.com.br

${ }^{3}$ Professor do Departamento de Ciência do Solo da Universidade Federal de Lavras/UFLA - Cx.P.3037 - Lavras, MG - niltcuri@ufla.br; jmarques@ufla.br ${ }^{4}$ Mestre em Ciência do Solo. Rua Carlos Gomes, no183 - Centro - 097515-530 - São Bernardo do Campo - SP - michele_duarte@ig.com.br
}

${ }^{4}$ Pesquisador da Aracruz Celulose S.A, Unidade Guaíba. Rua São Geraldo, 1800 - 92500-000 - Guaíba, RS - efaraujo@aracruz.com.br 
desapropriação e taxação de impostos (Dalmolin, 1999), além de ser útil em outras ciências básicas, como fitogeografia, geologia e arqueologia (Larach, 1983).

Mapas de solos em escala pequena não são adequados para o planejamento de uso das terras de microbacias hidrográficas, sendo necessários mapas em escala de 1:50.000 ou maiores, isto é, com informações detalhadas da distribuição dos diferentes tipos de solos na paisagem (Streck et al., 2008). Essas escalas são ainda pouco comuns no Rio Grande do Sul (Dalmolin et al., 2004), como no restante do país.

Em razão do baixo número de levantamentos executados em escalas iguais ou maiores do que 1:50.000, ao alto custo para sua execução, à carência de profissionais qualificados e à alta demanda por informações mais detalhadas, tem ocorrido a ampliação de mapas de levantamento de solos, de pequena escala (por exemplo: $1: 250.000 ; 1: 500.000 ; 1: 750.000$ ou 1:1.000.000), para elaboração de projetos em microbacias hidrográficas. Entretanto, a ampliação desses mapas de pequena escala não é um procedimento adequado (Dalmolin et al., 2004), podendo levar a interpretações incorretas acerca da real capacidade de uso das terras, comprometendo a sustentabilidade das mesmas. Para se obter informações detalhadas sobre a distribuição dos solos é necessária a realização de levantamentos em escala compatível com os objetivos que se pretende alcançar.

Diferenças entre mapas semidetalhado e ampliado do mapa de reconhecimento de solos foram observadas por Dalmolin et al. (2004) para os municípios de São João do Polésine, escala 1:20.000, e São Pedro do Sul, escala 1:50.000, comparando estes com o mapa ampliado a partir da escala 1:750.000 para o estado do Rio Grande do Sul. Os autores observaram que a grande variabilidade de solos existente nas áreas não foi delimitada no mapa de pequena escala, e que a utilização das informações do mapa ampliado conduziria ao uso inadequado das terras em relação a sua aptidão agrícola.

Com base no exposto, neste trabalho, objetivou-se executar o levantamento detalhado de solos de uma microbacia hidrográfica e comparar as informações do mapa detalhado confeccionado na escala 1:10:000, com aquelas dos mapas ampliados de solos extraídos do levantamento de reconhecimento do Estado do Rio Grande do Sul, na escala 1:750.000 (Brasil, 1973), e do levantamento exploratório, na escala 1:1.000.000 (IBGE, 1986), respectivamente, utilizando sistemas de informações geográficas (SIG).

\section{MATERIAL E MÉTODOS}

A área em estudo, denominada microbacia do Horto Florestal Terra Dura, está localizada no município de Eldorado do Sul - RS. É delimitada pelas coordenadas UTM 22K 440.902 e 441.931E e 6.662.028 e 6.660.462 S (Datum SAD 69). A microbacia compreende uma área total de 115,9 ha dos quais 88,5 ha, cultivados com eucalipto, correspondem à área de solos mapeada, e o restante da área corresponde à vegetação nativa preservada, estradas e outros usos. Na região, a vegetação primitiva é representada pela formação florestal designada Mata Subtropical Alta e Mata Subtropical Arbustiva. O clima é o "Cfa", subtropical ou virginiano (classificação de Köppen), com temperatura média do mês mais quente superior a $22^{\circ} \mathrm{C}$ e a do mês mais frio inferior a $18^{\circ} \mathrm{C}$, temperatura média anual de $19,1^{\circ} \mathrm{C}$ e precipitação média anual de $1440 \mathrm{~mm}$ (Brasil, 1973). A área está inserida na região fisiográfica Depressão Central e o relevo varia de plano a montanhoso, com altitudes variando de 85 a $185 \mathrm{~m}$. A geologia da área é composta de rochas ígneas, sienogranitos, correspondente à Suíte Intrusiva Dom Feliciano - Litofácies Serra do Herval, do Período Neoproterozóico (2500 Ma) (Ramgrab et al., 2004).

Nos trabalhos de campo, foram utilizados como material básico a carta planialtimétrica SH.22-Y-B-BII-2, folha Arroio dos Ratos, na escala 1:50.000, aerofotos policromáticas na escala aproximada de 1:60.000, bem como o levantamento planialtimétrico da microbacia em escala 1:10.000, com distância vertical entre curvas de nível igual a $5 \mathrm{~m}$. A prospecção da área foi realizada por meio do método do caminhamento livre, percorrendo toda a área e realizando observações e medições de campo sempre que havia indicação de mudança da classe de solo e/ou de seus atributos, com densidade de 0,56 observações por ha. Os pontos de observação foram georreferenciados em campo e foram coletadas amostras de solos, conforme Santos et al. (2005). Foram realizadas análises químicas e granulométricas do solo (Embrapa, 1997) e a classificação pedológica foi realizada segundo o Sistema Brasileiro de Classificação de Solos (Embrapa, 2006), com o apoio de perfis modais (Figura 1).

Após o trabalho de campo, as unidades de mapeamento (UMs) de solos foram delimitadas com auxílio do mapa base, utilizando sistemas de informações geográficas. Para definição das unidades de mapeamento de solos, foram considerados como atributos determinantes aqueles mais diretamente relacionados ao desenvolvimento da cultura do eucalipto.

Numa segunda etapa, foram gerados mapas de solos da microbacia a partir da ampliação do mapa de reconhecimento de solos do Rio Grande do Sul, escala 1:750.000, publicado por Brasil (1973) com legenda atualizada por Streck et al. (2008), e a partir da ampliação do mapa exploratório do IBGE (1986), escala 1:1.000.000. A 
nomenclatura dos solos do mapa ampliado do levantamento exploratório foi aqui atualizada (Embrapa, 2006), permitindo a comparação entre as unidades de mapeamento de solos existentes nos três levantamentos.

\section{RESULTADOS E DISCUSSÃO}

\section{Levantamento detalhado de solos}

Na Tabela 1, é apresentada a relação das unidades de mapeamento de solos observadas no levantamento detalhado da microbacia em estudo, além de atributos intrínsecos e extrínsecos das mesmas e sua expressão geográfica. Os valores analíticos dos atributos químicos e texturais podem ser observados na Tabela 2.

Na Figura 1, é mostrado o mapa de solos detalhado para a microbacia, onde observa-se a ocorrência de seis classes ao nível de subordem de solos e doze unidades de mapeamento de solos. Nos mapas ampliados (não apresentados), verificou-se a ocorrência de apenas uma classe ao nível de ordem e uma unidade de mapeamento, em razão das limitações de escala.

Dentre as 12 classes de solo identificadas, ocorreram 4 classes no $1^{\circ}$ nível categórico ( $\mathrm{P}$ - Argissolos, C - Cambissolos, N - Nitossolos e S - Planossolos), 6 classes no $2^{\circ}$ nível categórico (PA, PV, PVA, CX, NV e SX), 6 fases de textura $(\mathrm{m} / \mathrm{m} / \mathrm{r}, \mathrm{m} / \mathrm{rr} / \mathrm{rr}, \mathrm{m} / \mathrm{r} / \mathrm{r}, \mathrm{m} / \mathrm{r} / \mathrm{rr}, \mathrm{m} / \mathrm{m} / \mathrm{m} \mathrm{e} \mathrm{r} / \mathrm{r} / \mathrm{r})$ e 4 fases de relevo (ondulado, plano/suave ondulado; forte ondulado/montanhoso e plano de várzea) (Tabela 1), resultando da grande variabilidade espacial de solos e seus atributos numa área de dimensões relativamente restritas (116 ha).

Os Argissolos Vermelhos Alumínicos típicos (PVa) ocupam $42 \%$ (37 ha) da área mapeada e constituem a classe de maior abrangência geográfica. Os Cambissolos (CXbd1 e CXbd2) representam 9\% da área mapeada. Os Nitossolos Vermelhos Distróficos (NVd) correspondem a 4\% da área. As unidades Argissolos Vermelho-Amarelos (PVAd1, PVAd2, PVAa) e Argissolo Amarelo (PAd) ocupam, respectivamente, 4, 4, 11 e 4\% da área mapeada. O restante da área (3\%) é ocupada pela classe dos Planossolos Háplicos Eutróficos gleissólicos (SXe).

A grande maioria dos solos da microbacia é de baixa fertilidade (indicada pelo baixo valor $\mathrm{V}$ - saturação por bases), havendo 1 solo endoeutrófico (SX), explicado pela restrição de drenagem e posição receptora na paisagem local, e 2 epieutróficos (PVa e PVAa), explicados pelo efeito da calagem (valores de $\mathrm{Ca}^{2+} \geq 6 \mathrm{cmol}_{\mathrm{c}} \mathrm{dm}^{-3}$ ), os quais paradoxalmente são alumínicos (altos valores de $\mathrm{Al}^{3+} \mathrm{e}$ atributos correlatos) em profundidade (Tabela 2).

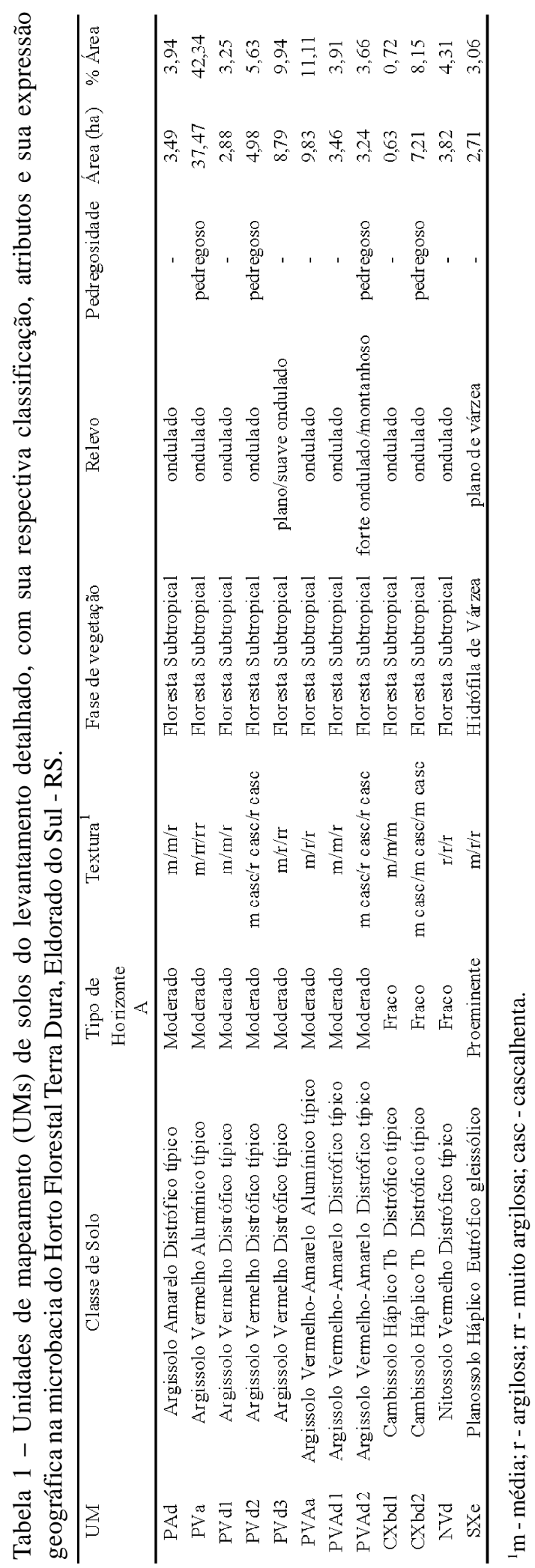


Tabela 2 - Dados médios dos valores dos atributos químicos e granulométricos das Unidades de Mapeamento (UMs) do levantamento detalhado de solos da microbacia do Horto Florestal Terra Dura, Eldorado do Sul - RS.

\begin{tabular}{|c|c|c|c|c|c|c|c|c|c|c|c|c|c|c|c|}
\hline $\mathrm{UM}^{1}$ & Horiz. & $\mathrm{pH}^{2}$ & C org. ${ }^{3}$ & $\mathrm{P}$ & $\mathrm{K}$ & $\mathrm{Ca}$ & $\mathrm{Mg}$ & $\mathrm{Al}$ & SB & $\mathrm{T}$ & $\mathrm{V}$ & $\mathrm{m}$ & Argila & Silte & Areia \\
\hline & & & $\mathrm{g} \mathrm{kg}^{-1}$ & ---mg & $\mathrm{m}^{-3}--$ & ----- & - & $\mathrm{cmol}_{\mathrm{c}}$ & $\mathrm{m}^{-3}--$ & ----- & $---c$ & -- & $------d$ & g. $\mathrm{kg}^{-1}-$ & - \\
\hline \multirow[t]{3}{*}{ PAd } & Ap & 5,1 & 8,1 & 1,2 & 55 & 1,0 & 0,5 & 1,5 & 1,7 & 8,0 & 21,3 & 47 & 14 & 35 & 51 \\
\hline & BA & 5,1 & 8,1 & 0,6 & 59 & 0,8 & 0,2 & 2,6 & 1,2 & 12,2 & 9,9 & 68 & 20 & 31 & 49 \\
\hline & $\mathrm{Bt}$ & 5,1 & 2,9 & 0,4 & 59 & 1,6 & 3,7 & 10,4 & 5,6 & 29,5 & 19,0 & 65 & 40 & 38 & 22 \\
\hline \multirow[t]{3}{*}{$\mathrm{PVa}$} & Ap & 6,2 & 16,8 & 6,8 & 48 & 7,0 & 0,9 & 0,0 & 8,1 & 10,2 & 79,4 & 0 & 19 & 21 & 60 \\
\hline & Bt1 & 4,7 & 5,8 & 0,9 & 29 & 0,3 & 0,1 & 4,2 & 0,5 & 12,8 & 3,7 & 90 & 66 & 15 & 19 \\
\hline & Bt2 & 4,9 & 1,2 & 0,9 & 19 & 0,6 & 0,1 & 4,4 & 0,7 & 14,7 & 5,1 & 85 & 77 & 10 & 13 \\
\hline \multirow[t]{3}{*}{ PVd1 } & Ap & 4,6 & 7,5 & 3,1 & 33 & 0,7 & 0,2 & 1,3 & 1,0 & 5,5 & 18,2 & 57 & 13 & 16 & 71 \\
\hline & BA & 4,8 & 2,9 & 1,7 & 75 & 0,8 & 0,2 & 2,2 & 1,2 & 10,0 & 12,1 & 65 & 24 & 20 & 56 \\
\hline & $\mathrm{Bt}$ & 4,9 & 13,9 & 1,4 & 67 & 0,8 & 0,2 & 3,0 & 1,2 & 12,2 & 9,8 & 72 & 35 & 20 & 45 \\
\hline \multirow[t]{3}{*}{$\mathrm{PVd} 2$} & Ap & 5,0 & 8,1 & 1,4 & 56 & 1,4 & 0,6 & 1,1 & 2,2 & 6,7 & 32,5 & 34 & 18 & 17 & 65 \\
\hline & Bt1 & 4,6 & 8,1 & 0,6 & 69 & 0,7 & 0,2 & 3,4 & 1,1 & 16,4 & 6,8 & 75 & 40 & 19 & 41 \\
\hline & Bt2 & 5,0 & 2,9 & 0,6 & 28 & 0,4 & 1,7 & 3,4 & 2,3 & 16,0 & 14,2 & 60 & 54 & 17 & 29 \\
\hline \multirow[t]{3}{*}{ PVd3 } & Ap & 4,7 & 8,1 & 1,4 & 90 & 1,4 & 1,2 & 1,1 & 2,9 & 7,4 & 38,8 & 28 & 18 & 23 & 59 \\
\hline & BA & 5,0 & 21,5 & 0,4 & 90 & 1,4 & 0,6 & 2,1 & 2,3 & 12,1 & 18,7 & 48 & 35 & 20 & 45 \\
\hline & $\mathrm{Bt}$ & 5,0 & 12,8 & 0,4 & 94 & 2,6 & 2,4 & 1,5 & 5,3 & 12,3 & 43,1 & 22 & 71 & 11 & 18 \\
\hline \multirow[t]{3}{*}{ PVAa } & Ap & 6,0 & 18,0 & 1,7 & 98 & 6,0 & 2,6 & 0,0 & 8,9 & 11,6 & 77,5 & 0 & 23 & 39 & 38 \\
\hline & Bt1 & 5,3 & 7,5 & 0,6 & 50 & 1,0 & 1,4 & 5,1 & 2,5 & 11,4 & 22,1 & 67 & 59 & 27 & 14 \\
\hline & Bt2 & 5,6 & 2,3 & 0,6 & 20 & 0,4 & 1,5 & 6,6 & 2,0 & 10,7 & 18,3 & 77 & 55 & 22 & 23 \\
\hline \multirow[t]{3}{*}{ PVAd1 } & Ap & 4,9 & 8,7 & 1,2 & 47 & 0,6 & 0,2 & 1,6 & 1,0 & 6,0 & 16,1 & 63 & 13 & 20 & 67 \\
\hline & $\mathrm{E}$ & 5,2 & 5,8 & 0,9 & 47 & 0,7 & 0,2 & 1,2 & 1,1 & 5,6 & 18,9 & 53 & 12 & 23 & 65 \\
\hline & $\mathrm{Bt}$ & 5,2 & 30,7 & 0,4 & 87 & 0,8 & 0,2 & 2,9 & 1,3 & 11,1 & 11,6 & 69 & 35 & 20 & 45 \\
\hline \multirow[t]{3}{*}{ PVAd2 } & Ap & 5,0 & 10,4 & 105,1 & 62 & 1,7 & 0,5 & 1,2 & 2,4 & 8,7 & 27,9 & 33 & 18 & 34 & 48 \\
\hline & Bt1 & 5,1 & 8,7 & 1,4 & 59 & 0,8 & 0,2 & 1,7 & 1,2 & 9,1 & 13,0 & 59 & 35 & 24 & 41 \\
\hline & $\mathrm{Bt} 2$ & 5,2 & 2,9 & 0,4 & 76 & 1,0 & 0,3 & 2,0 & 1,5 & 7,8 & 19,6 & 56 & 36 & 26 & 38 \\
\hline \multirow[t]{3}{*}{ CXbd 1} & Ap & 5,0 & 14,5 & 1,7 & 0 & 1,4 & 1,5 & 1,6 & 3,0 & 12,8 & 23,4 & 35 & 25 & 31 & 44 \\
\hline & Bil & 5,0 & 11,0 & 0,4 & 92 & 1,1 & 1,9 & 3,9 & 3,4 & 15,7 & 21,6 & 54 & 34 & 34 & 32 \\
\hline & $\mathrm{Bi} 2$ & 5,4 & 2,3 & 0,4 & 39 & 1,4 & 4,9 & 3,9 & 6,6 & 20,3 & 32,5 & 37 & 34 & 30 & 36 \\
\hline \multirow[t]{3}{*}{ CXbd2 } & Ap & 5,1 & 14,4 & 1,5 & 40 & 1,3 & 1,6 & 1,5 & 3,0 & 13,0 & 23,1 & 33 & 26 & 30 & 44 \\
\hline & Bil & 4,9 & 11,1 & 0,3 & 90 & 1,0 & 1,8 & 3,8 & 3,0 & 15,0 & 20,2 & 56 & 33 & 35 & 32 \\
\hline & $\mathrm{Bi} 2$ & 5,3 & 2,4 & 0,3 & 41 & 1,3 & 4,6 & 3,7 & 6,0 & 19,0 & 31,6 & 38 & 34 & 29 & 37 \\
\hline \multirow[t]{3}{*}{$\mathrm{NVd}$} & Ap & 5,0 & 9,3 & 1,4 & 55 & 1,9 & 0,9 & 1,7 & 3,0 & 10,9 & 27,5 & 36 & 36 & 17 & 47 \\
\hline & Bt1 & 4,8 & 3,5 & 0,4 & 31 & 0,7 & 0,2 & 3,8 & 1,0 & 14,7 & 6,9 & 79 & 39 & 17 & 44 \\
\hline & Bt2 & 4,8 & 7,0 & 0,4 & 12 & 0,8 & 0,2 & 3,4 & 1,1 & 10,9 & 9,7 & 76 & 37 & 23 & 40 \\
\hline \multirow[t]{3}{*}{ SXe } & Ap & 4,8 & 14,5 & 2,0 & 56 & 1,3 & 1,1 & 2,4 & 2,6 & 13,6 & 19,4 & 48 & 17 & 41 & 42 \\
\hline & Bt1 & 5,4 & 5,8 & 0,9 & 40 & 5,1 & 6,0 & 2,7 & 11,2 & 22,2 & 50,5 & 27 & 35 & 33 & 32 \\
\hline & Bt2 & 6,1 & 1,2 & 0,6 & 20 & 3,9 & 3,0 & 0,2 & 7,5 & 9,2 & 81,5 & 3 & 36 & 26 & 38 \\
\hline
\end{tabular}

${ }^{1}$ Unidades de mapeamento: PAd - Argissolo Amarelo Distrófico típico; PVa - Argissolo Vermelho Alumínico típico pedregoso; PVd1Argissolo Vermelho Distrófico típico; PVd2 - Argissolo Vermelho Distrófico típico pedregoso; PVd3 - Argissolo Vermelho Distrófico típico; PVAa - Argissolo Vernelho-Amarelo Alumínico típico; PVAd1 - Argissolo Vermelho-Amarelo Distrófico típico; PVAd2 Argissolo Vermelho-Amarelo Distrófico típico pedregoso; CXbd1 - Cambissolo Háplico TB Distrófico típico; CXbd2 - Cambissolo Háplico Tb Distrófico pedregoso; NVd - Nitossolo Vermelho Distrófico típico; SXe - Planossolo Háplico Eutrófico gleissólico; ${ }^{2} \mathrm{pH}$ em $\mathrm{H}_{2} \mathrm{O}$ (relação 1:2,5); ${ }^{3}$ Carbono orgânico; $\mathrm{P}$, K: extrator ( $\left.\mathrm{HCl} \quad 0,05 \mathrm{~mol} \mathrm{~L}^{-1}+\mathrm{H}_{2} \mathrm{SO}_{4} 0,025 \mathrm{~mol} \mathrm{~L}^{-1}\right)$; $\mathrm{Al}, \mathrm{Ca}, \mathrm{Mg}$ : extrator $(\mathrm{KCl} 1 \mathrm{~mol} \mathrm{~L}$ 1); SB: soma de bases; T: CTC a pH 7,0; V: saturação por bases; m: saturação por alumínio. 

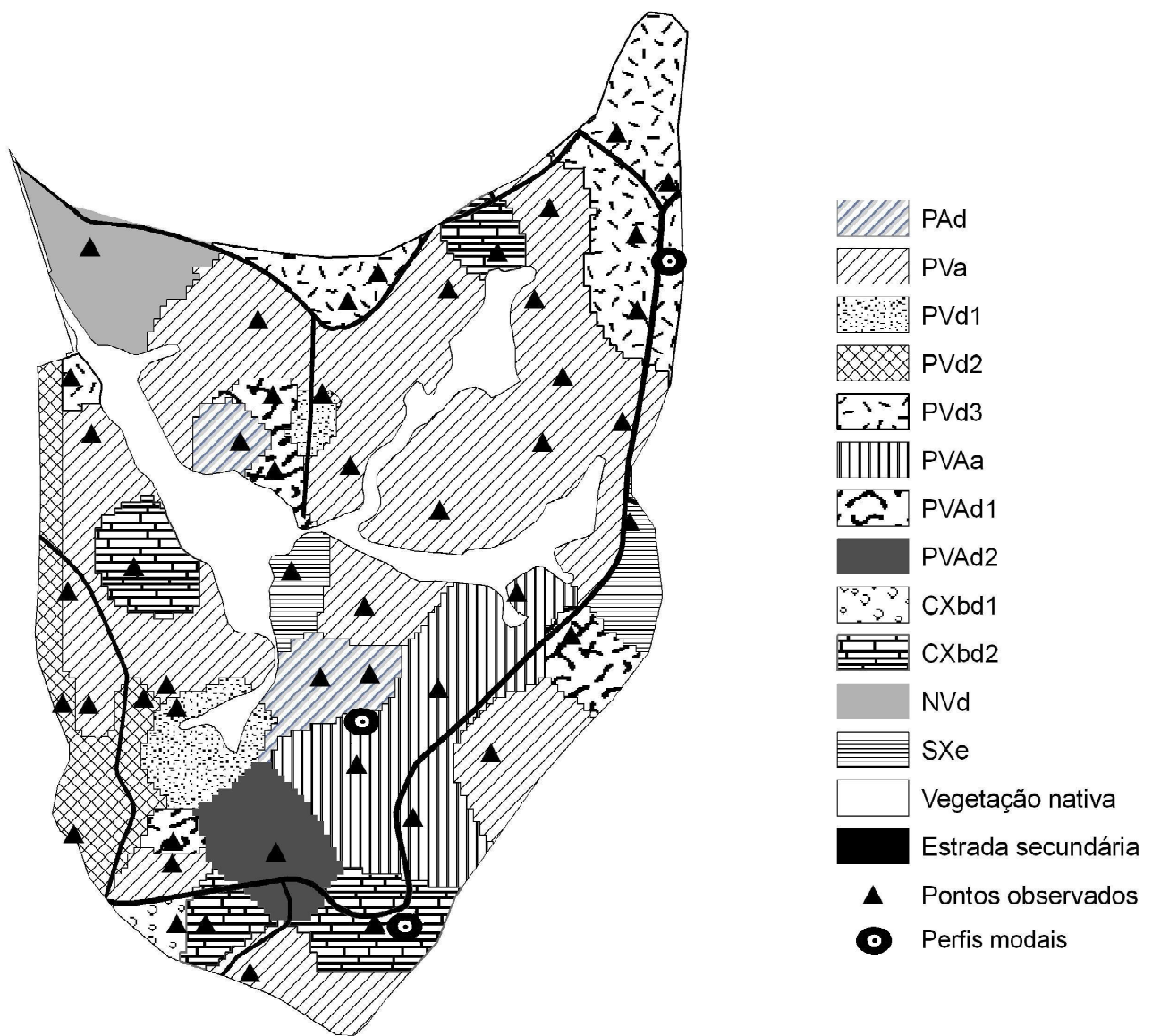

Figura 1 - Mapa detalhado de solos da microbacia do Horto Florestal Terra Dura (RS). Detalhes da legenda podem ser vistos na Tabela 1

O gradiente textural é mais elevado nos Argissolos e no Planossolo, e mais baixo nos Cambissolos e no Nitossolo, sendo que este último revelou cerosidade em quantidade abundante e grau de desenvolvimento forte (Santos et al., 2005), atributos suficientes para seu enquadramento como horizonte B nítico (Embrapa, 2006).

\section{Comparação do mapeamento detalhado de solos com mapeamentos mais generalizados}

Tanto para o mapa ampliado do levantamento de reconhecimento (Brasil, 1973), quanto para o exploratório (IBGE, 1986), apenas uma unidade de mapeamento contempla a área total da microbacia. No primeiro caso, foi delimitada apenas a unidade de mapeamento, PVd7, Argissolo Vermelho Distrófico típico textura média/ argilosa, que corresponde no levantamento detalhado do presente trabalho aproximadamente ao PVd3. No segundo caso, foi delimitada apenas a unidade de mapeamento PEa6, associação de Argissolo Vermelho + Argissolo VermelhoAmarelo ambos Distróficos típicos textura média/argilosa, que corresponde no levantamento detalhado do presente trabalho aproximadamente ao PVd3 e PVAd1.

No levantamento detalhado, a unidade PVd3 representa apenas $10 \%$ da área da microbacia e a unidade PVAd1 representa somente $4 \%$, o que pode implicar em interpretações errôneas no que se refere ao planejamento de atividades na microbacia se este fosse realizado a partir da ampliação dos mapas de solos, sem uma checagem adequada de campo.

Para o mapa ampliado do levantamento exploratório, a capacidade de uso dos recursos naturais renováveis correspondente à área da microbacia (IBGE, 1986), apresenta como características pedológicas mais restritivas a estrutura (blocos) e a textura (argilosa) do horizonte B, além da soma de bases (baixa), o que em $75 \%$ da microbacia é genericamente pertinente (unidades PAd, PVa, PVd1, PVd3, PVAa e PVAd1). 
No levantamento de reconhecimento de solos, na escala 1:750.000, a área mínima mapeável (AMM) é de 2.250 ha, ou seja, unidades de solos que ocupam áreas inferiores a esta não farão parte da legenda do mapa de solos. Já para o levantamento exploratório, na escala 1:1.000.000, a AMM é de 4.000 ha. Essas AMMs são maiores do que a área da microbacia (116 ha). No levantamento detalhado, na escala 1:10.000, a AMM é de 0,4 ha. Na microbacia estudada, as unidades de solos delimitadas no levantamento detalhado apresentam área mínima de 0,63 ha (CXbd1). A utilização direta das informações dos mapas ampliados dos levantamentos de reconhecimento e exploratório estaria minimizando algumas limitações relativas à aptidão silvicultural das terras para o cultivo do eucalipto, visto que solos de maior fragilidade ambiental como os Cambissolos e Planossolos, não foram contemplados nos mapas ampliados em questão.

A utilização de mapas de levantamentos de solos em escala inadequada pode trazer como consequência a má utilização dos recursos naturais, com a degradação dos solos e obtenção de rendimentos e lucros abaixo do potencial regional (Giasson et al., 2006). E ainda, ao considerar grandes áreas como homogêneas, pode haver implicações quanto ao uso de fertilizantes, satisfazendo apenas as necessidades médias das plantas com relação a estes insumos (Souza et al., 2007). Para um adequado uso do solo, torna-se necessária a execução de levantamentos de solos em escala condizentes com os objetivos que se pretende alcançar.

Ressalta-se, entretanto, que os mapas do levantamento de reconhecimento de solos, na escala $1: 750.000$, e o mapa exploratório, na escala 1:1.000.000, apresentam informações condizentes para execução de projetos e planejamentos em áreas maiores.

$\mathrm{Na}$ Tabela 3, sintetizam-se as comparações progressivas, partindo dos diferentes campos da legenda,entre os mapas de solos em pauta. Em se tratando de uma microbacia hidrográfica, onde informações detalhadas são requeridas, verifica-se a conveniência da utilização do mapa de solos em escala 1:50.000 ou maior (Streck et al., 2008), no presente trabalho 1:10.000. 


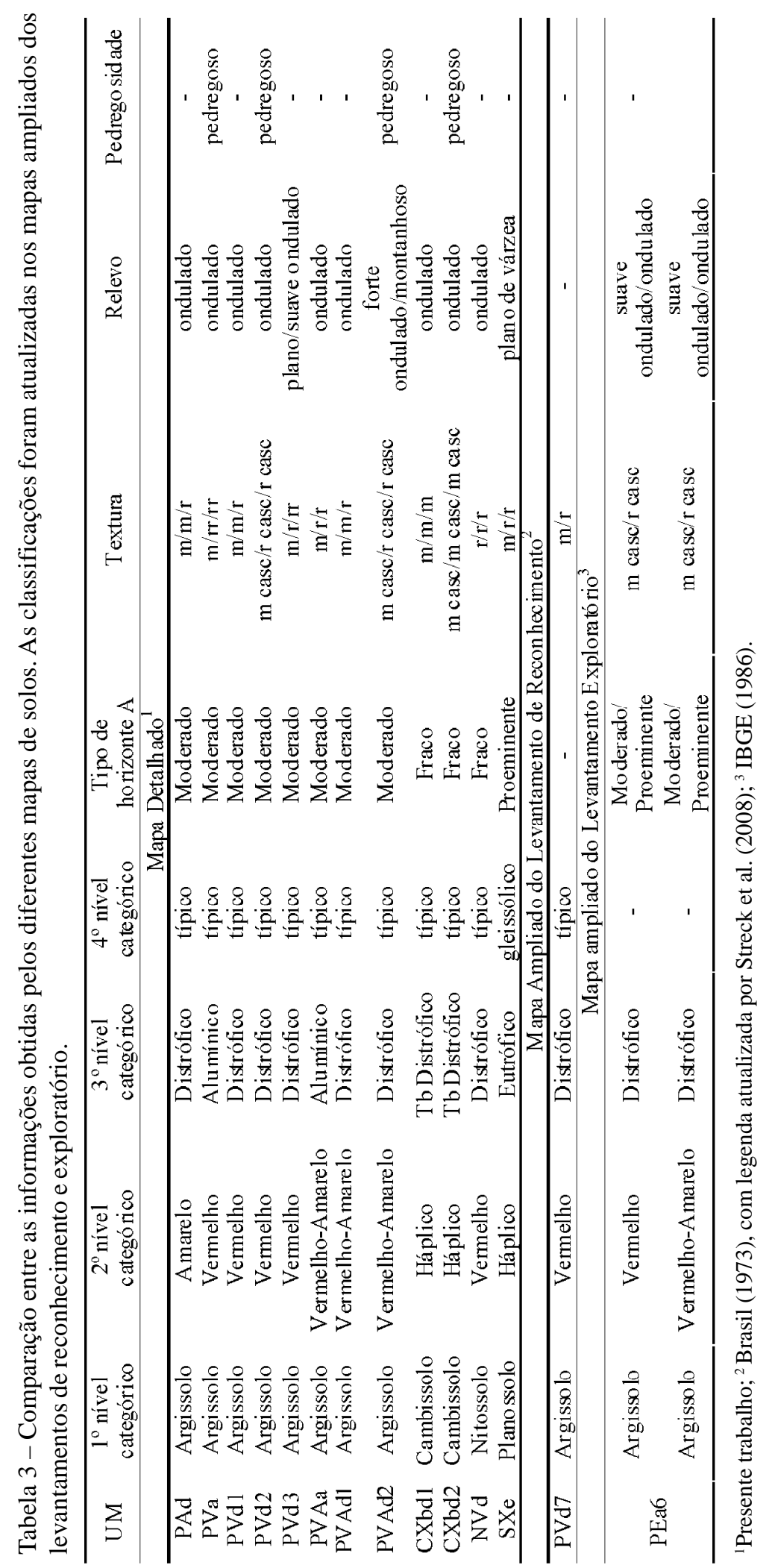

Ciênc. agrotec., Lavras, v. 33, n. 5, p. 1272-1279, set./out., 2009 


\section{CONCLUSÕES}

Foram delimitadas doze unidades de mapeamento de solos no mapa do levantamento detalhado e apenas uma unidade nos mapas ampliados dos levantamentos de reconhecimento e exploratório.

Em termos de informações para o cultivo sustentável do eucalipto, limitações relativas à fertilidade do solo, suscetibilidade à compactação e erosão, infiltração de água no solo, profundidade efetiva e risco de anoxia ficaram ausentes nos mapas de escala pequena ampliados em aproximadamente $40 \%$ da área da microbacia estudada.

\section{AGRADECIMENTOS}

Á EMATER- RS, na pessoa do Dr. Edemar Streck, pelo acesso às informações do mapa digital de solos do Rio Grande do Sul.

\section{REFERÊNCIAS BIBLIOGRÁFICAS}

BRASIL. Ministério da Agricultura. Levantamento de reconhecimento dos solos do estado do Rio Grande do Sul. Recife: MA/DPP-AS/DRNR, 1973. 431p. (Boletim técnico, 30).

DALMOLIN, R.S.D. Faltam pedólogos no Brasil. Boletim Informativo da Sociedade Brasileira de Ciência do Solo, Viçosa, v.24, n.4, p.13-15, out./dez. 1999.

DALMOLIN, R.S.D.; KLAMT, E.; PEDRON, F. de A.; AZEVEDO, A.C. de. Relação entre as características e o uso das informações de levantamentos de solos de diferentes escalas. Ciência Rural, Santa Maria, v.34, n.5, p.1479-1486, set./out. 2004.

\section{EMPRESA BRASILEIRA DE PESQUISA}

AGROPECUÁRIA. Manual de métodos de análises de solo. 2.ed. Rio de Janeiro, 1997. 212p.

\section{EMPRESA BRASILEIRA DE PESQUISA}

AGROPECUÁRIA. Centro Nacional de Pesquisa de Solos. Sistema brasileiro de classificação de solos. 2.ed. Rio de Janeiro, 2006. 306p.

GIASSON, E.; INDA JÚNIOR, A.V.; NASCIMENTO, P.C. Estimativa do benefício econômico potencial de dois levantamentos de solos no Estado do Rio Grande do Sul. Ciência Rural, Santa Maria, v.36, n.2, p.478-486, mar./abr. 2006.

\section{INSTITUTO BRASILEIRO DE GEOGRAFIA E}

ESTATÍSTICA. Radambrasil: folha SH2 - Porto Alegre. Rio de Janeiro, 1986. 791p.

LARACH, J.O.I. Usos de levantamento de solos. Informe Agropecuário, Belo Horizonte, v.9, n.109, p.2632, set. 1983.

MENEZES, M.D. Levantamento de solos em sub-bacia hidrográfica como apoio para avaliação do uso da terra e da potencialidade de recarga de aquíferos. 2007. 107p. Dissertação (Mestrado)-Universidade Federal de Lavras, Lavras, 2007.

RAMGRAB, G.E.; WILDNER, W.; LOPES, R.C.; FAVILLA, C.A.C.; SILVA, M.A.S.; SACHS, L.L.B.; SILVA, V.A.; BATISTA, I.H. Ramdabrasil: folha SH. 22 - Porto Alegre. In: SCHOBBENHAUS, C.; GONÇALVES, J.H.; SANTOS, J.O.S.; ABRAM, M.B.; LEÃO NETO, R.; MATOS, G.M.M.E.; VIDOTTI, R.M.; RAMOS, M.A.B.; JESUS, J.D.A. de (Eds.). Carta geológica do Brasil ao milionésimo, sistema de informações geográficas: programa geologia do Brasil. Brasília, DF: CPRM, 2004. CD-ROM.

RESENDE, M.; REZENDE, S.B. Levantamento de solos: uma estratificação de ambientes. Informe Agropecuário, Belo Horizonte, v.9, n.105, p.3-25, set. 1983.

SILVA, F. M. da; SOUZA, Z. M. de; FIGUEIREDO, C. A. P. de; VIEIRA, L. H. de S.; OLIVEIRA, E. de. Variabilidade espacial de atributos químicos e produtividade da cultura do café em duas safras agrícolas. Ciência e Agrotecnologia, Lavras, v.32, n.1, p.231-241, jan./fev., 2008.

SOUZA, Z. M. de; BARBIERI, D. M.; MARQUES JÚNIOR, J.; PEREIRA, G. T.; CAMPOS, M. C. C. Influência da variabilidade espacial de atributos químicos de um latossolo na aplicação de insumos para cultura de cana-de-açúcar. Ciência e Agrotecnologia, Lavras, v. 31, n.2, p. 371-377, mar./abr.; 2007.

SANTOS, R.D.; LEMOS, R.C.; SANTOS, H.G.; KER, J.C.; ANJOS, L.H.C. Manual de descrição e coleta de solos no campo. 5.ed. Viçosa, MG: SBCS, 2005. 92p.

STRECK, E.V.; KÄMPF, N.; DALMOLIN, R.S.D.; KLAMT, E.; NASCIMENTO, P.C. do; SCHNEIDER, P.; GIASSON, E.; PINTO, L.F.S. Solos do Rio Grande do Sul. 2.ed. rev. e ampl. Porto Alegre: Emater/RS, 2008. 222p. 